\title{
CHALLENGES AND CONSTRAINTS OF USING AUDIO IN ONLINE MUSIC EDUCATION
}

\author{
Paulo R. A. Marins \\ Universidade de Brasília, \\ Departament of Music, \\ Campus Universitário Darcy Ribeiro, Prédio SG-2 \\ CEP: 70.910-900 - Caixa Postal 4432 \\ Asa Norte - Brasília-DF, Brazil \\ pramarins@gmail.com
}

\begin{abstract}
Several online music courses have been developed lately by educational companies. In addition, many universities have been offering music online degree programs. Since these courses and programs are taught through distance education, many ICTs are used such as: recorded video, online software, social networks, and audio. Although audio is widely used in the online courses and degree programs that aim to teach applied music, only a few research reports have been published recently about this subject. This paper intends to clarify - through a literature review - some questions concerning this use and also aims to provide a discussion regarding the challenges and constraints of using audio in online applied music lessons. It is also hoped that the discussions made in this paper may lead to the development of research in the area of online music education as well as in the specific field of sound in learning.
\end{abstract}

\section{INTRODUCTION}

Online music instruction has been growing throughout the world at all levels, from elementary to higher education. In the US, for instance, there are 13 (thirteen) graduate and 1 (one) undergraduate online degree program in music that are NASM (National Association Schools of Music) accredited. In $n$ Brazil, there are 3 undergraduate online degree programs in music education that are offered by public universities. Moreover, there are many other online resources such as Massive Open Online Courses (MOOCs) and Open Educational Resources (OER) that have courses on many aspects of music, such as music businesses, applied music, and so forth. This type of education is mediated by Information and Communication Technologies (ICT), and according to [1], although these technologies are widely used in the online courses and degree programs that aim to teach music online, only a few research reports have been published recently about this subject. Nonetheless, there have been have been many studies regarding the use of ICT in general teaching and learning processes online. [2] discuss the various technologies and media available for distance education. They state that different media can be used in the teaching and learning processes involved in online education. At the time they wrote the book (2007), printed materials (textbooks, manuals, course notes, and study guides) were the most common medium used in distance education. They also state that audio media it is underused and neglected by educators. Additionally, they emphasize that technology must be reliable and the video and sound quality must be good enough in order to not interfere with the message that is going to be delivered by the instructor. [2] also question the Internet2 and its availability, as according to them - up to date - this type of internet is not available in all schools and universities in the world. Another key statement that the authors make is that educators tend to stick to a particular technology and deliver all the content of their course using that particular ICT. They also say that no matter how well designed the content is, it does not mean that the students are going to use it. It can be inferred then that it is also important to acquire feedback from the students after designing a course. Moreover, regarding the specific use of some digital technologies, [3] for instance, states that audio activates more than one sensory channel and consequently contemplates different profile of learners. [3] also highlights the advantages of employing multimedia content as - according to the researcher - they can: help developing skills, allow multiple modalities of learning, enhance the interactivity, leave the student choose whether he wants to learn individually or not, allow a better comprehension and therefore can be helpful in all of the stages of the learning processes. [4] points that the main advantage of the use of ICT is that the distance, which is intrinsic to the distance education modality, can become proximity as applications such as audio and video conferencing can allow a simultaneous dialogue between teachers and students. However, if using audio in online music education can enhance the learning process - as the aforementioned researchers state - it is then useful to understand why audio being underused in this modality of education as well as the challenges and constraints of using this specific type of media in online music education.

\section{AUDIO IN ONLINE MUSIC EDUCATION}

Although underused - as stated by some researchers cited above - audio is normally employed in online music instruction in a number of ways, such as: recorded audio files in order to provide musical examples or a 'library'; a recorded video lesson (audio in this case is usually recorded and edited 
separately), or in a web conference in which instructor and students can have a synchronous communication and audio of the conference is streamed through the web. In order to illustrate the underuse of audio in online music education it is worth mentioning the study of [5], who conducted a research about learning objects in the guitar course of the distance education undergraduate degree program in music of Universidade ode Brasília - UnB, Brazil. From more than 300 (three hundred) learning objects found in the course, only 5 (five) were audio files. This may be related to the fact that - to the author's knowledge - most of the studies concerning the use of audio in online music education are related to video or web conferencing. Additionally, [6] conducted a research about teaching guitar online in the distance education undergraduate degree program in music education of Universidade Federal do Rio Grande do Sul - UFRGS, Brazil. He concluded that - despite technical problems that might occur - videoconferencing is the most effective tool for teaching guitar master-classes online. This might explain the number of studies related to the use of videoconferencing for teaching music online as well as the fact that the research works about the use of audio in online music education is focused on videoconferencing. [7] analyzed the use of videoconferencing technology by investigating a college professor who taught applied music lessons to an eighth grade trumpet student. The researcher states that videoconferencing based lessons face lots of challenges in aspects such as visual limitations, body movement, audio and video delay, and sound volume control. 2 (two) of the problems listed by [7] (delay and volume control) are related to audio. [7] then concluded that videoconferencing based lessons although feasible still could not replace face-to-face lessons, but rather could be used as a supplement for music instruction. The researcher was not the only researcher to mention technology constraints in videoconferencing based music education. [8] investigated the viability of piano lessons through the use of videoconferencing program Skype. Due to the lack of Internet 2 in Zambia, where the study took place, the cited researchers affirmed that the students in their study had to download video content rather than stream. This might be related to what [1] affirms, when the researcher states that good quality videoconference is a recent technology and restricted to limited populations. It is also worth mentioning that videoconference software like the aforementioned Skype was not developed for broadcasting music but rather to convey speech. Thus the frequency range of the videoconference audio content is between 80 to $80.000 \mathrm{~Hz}$ - whereas it is known that the frequency range of the human hearing is approximately 20 to $20.000 \mathrm{~Hz}$. Therefore - in an applied music lesson for instance - it might be difficult for the instructor to give feedback to their students, especially in terms of artistic and aesthetic aspects of music [9]. For this reason, this type of software cannot be considered as ideal for music lessons, although it can be very useful in terms of oral communication between the instructor and the student. Also, even with a good internet connection there is some audio compression involved in the process and this may interfere in a music lesson. According to [10] this compression can make the job of a music teacher difficult in terms of the perception of certain aspects of the performance of a student. For the reasons listed above, [10] affirms that videoconferencing software as Skype is not ideal for online music instruction. Another common issue in synchronous communication is the so-called latency. This occurs due to the fact that there is a number of data conversion steps involved in the audio stream process (the analog sound is captured by the microphone, converted to digital and then converted into a format that can be transmitted), and in each conversion step can generate a delay effect or the so-called encoding latency. Obviously that latency can interfere in the perception of the sound produced by an instrument of a student. For addressing this issue, the Conservatorio di Musica Giuseppi Tartini (Trieste,Italy) developed a piece of software called Low Latency (LOLA). An initial research conducted by [11] in order to investigate the potential of the referred piece of software in terms of online simultaneous music performance and distance learning. The experiment involved a classical masterclass, a jazz lesson, and an old-time fiddle session. The researchers compared LOLA to other videoconferencing software such as Skype and Polycom. The results indicated that LOLA seems to be more efficient than Skype and Polycom in terms of online music making, teaching and learning. However, [11] state that - although the software is free - LOLA requires specific equipment with estimated costs of $\$ 5.386$ which can prevent some schools, universities and professionals to use the referred software. Moreover, [12], in a recent study in which the researcher investigated instructors and students' behaviors in online music lessons found that the quality of the audio and visual interaction is central to the achievement of instructional success.

\section{INITIAL REMMARKS}

Based on the above discussion, some initial remarks can be made concerning challenges and constraints about using audio in online music education.

Audio is underestimated and underused. Researcher such as [2] and [5] support this argument. This occurs despite the fact that [3] reinforces the effectiveness of audio in online music education.

Although audio can be used many ways for teaching music online such as: an audio recorded lesson; a recorded music example; an audio library; a play along file, and so forth, the research studies tend to focus on the use of audio in videoconferencing or synchronous applications. One possible explanation for this may lie on the fact that - according to [4] - synchronous ICT may turn the distance which is intrinsic to online music education into proximity. Thus the use of video and web conferencing and therefore the focus on audio used in these type of applications.

Standard videoconferencing software available are not developed for music education. Unfortunately, this can compromise the effectiveness of the music learning process. Nonetheless, new technologies are being developed [10] [11] and the results are promising. Thus, it can be inferred that this issue it is likely to be addressed in a near future.

There are still many technical constraints that may prevent instructors to use audio in online music education. Some of them are related to: Internet connection, the aforementioned inadequate software, latency, data compression, audio delay, volume control, and so forth. Although some of these can be minimized by the use of adequate equipment, it is worth mentioning that technology is still not accessible to everyone being restricted to limited populations [1]. 


\section{FUTURE RESEARCH}

Based on the literature and also on the discussion made above, some possible research topics can be elicited concerning audio in online music education.

Research about asynchronous audio, for instance, since to this author's knowledge there is little research about this topic and there are other possibilities of using audio in online music education rather than in video or web conferencing. It would also be worth investigating the specificities of audio in videoconferencing. The studies discussed in this paper tend to focus on many aspects of the videoconferencing but not particularly on audio.

Music education researchers should also try to develop online free applications for online music education taken into aspect the specificities of music. Although the results of LOLA are promising, this piece of software requires equipment that may not be accessible for populations that live in poor areas. This paper - through a discussion based on the literature aimed bring some questions concerning the challenges and constraints of using audio in online music education. In addition, some initial remarks could be drawn from the literature researched and some possible research topics were elicited. It is hope that the discussion made here may be useful for researchers of the field and also may help in the development of the research in the area of distance music education.

\section{REFERENCES}

[1] J. Bowman, "Online Learning in Music. Foundations, Frameworks, and Practices". Oxford University Press : New York, 2014.

[2] M. Moore and G. Kearsley "Educação a distância: uma visão integrada". Tradução: Roberto Gelman. São Paulo: Cengage Learning. 2007.

[3] P. Fahy, P. "Media characteristics and online learning technology. In: Anderson, T and Elioumi, F., "Theory and Practice of Online Learning“Athabasca,cde.athabascau.ca/online_book, 2004.

[4] O. Peters, O. "Didática do Ensino a Distância". São Leopoldo, Editora Unisinos, 2001.

[5] P.R. L. Figueirôa, P. R. L. "Um Estudo sobre Objetos de Aprendizagem no Âmbito do Curso de Licenciatura em Música a Distância da UnB". Trabalho de Conclusão de Curso. Universidade de Brasília. 2016

[6] P.D.A Braga. "Oficina de violão: estrutura de ensino e padrões de interação em um curso coletivo a distância”.Tese de Doutorado em Música. Universidade Federal da Bahia. 2009.

[7] R. J. Dammers, "Utilizing internet-based videoconferencing for instrumental music lessons". Update: Application of Research in Music Education, 28 (1). 17-24, 2009.

[8] N.B. Kruse, S.C. Harlos, R. M. Callaha, and M.L. Herring. "Skype Music Lessons in the Academ: Intersections of Music Education, Applied Music and Technology". In: Journal of Music, Technology \& Education, v.6, nr1, pp 4360, 2013.

[9] B.K. Sheppard, G. Howe, G, and T. Snook . "Internet 2 and Musical Applications". Proceedings of the National Association of Schools of Music 84th Annual Meeting, Seattle. 2008.

[10] D. Gohn. "Educação Musical com as tecnologias da EaD”. In: Música e Educação: Série Diáologos com o Som. Editora da Universidade do Estado de Minas Gerais. Barbacena. 2015.

[11] H. Riley, R. Macleod, M. Libera. "Low Latency Audio Video Potentials for Collaborative Music Making Through Distance Learning”. In: Update: Applications of Research in Music Education. Published online. DOI: 10.1177/8755123314554403. 2014

[12] K. J. Dye, "Student and instructors behaviors in online music lessons: An exploratory study". International Journal of Music Education, 34 (2): 161-170. 2016.

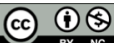

This work is licensed under Creative Common Attribution - Non Commercial 4.0 International License. The full terms of the License are available at http://creativecommons.org/licenses/by-nc/4.0/ 